\title{
FUNCIONES SECUNDARIAS DE LA CORTE CONSTITUCIONAL COLOMBIANA: UNA APROXIMACIÓN A LA DECISIÓN SOBRE EXCUSAS A LOS EMPLAZAMIENTOS CURSADOS POR EL CONGRESO
}

RODRIGO GONZÁLEZ QUINTERO LUIS JAVIER MORENO ORTIZ 
SUMARIO

INTRODUCCIÓN. I. APROXIMACIÓN AL SISTEMA DE CONTROL CONSTITUCIONAL EN COLOMBIA. II. COMPETENCIAS ADICIONALES, ADJUNTAS O ATIPICAS AL CONTROL CONSTITUCIONAL: DISCUSIÓN Y ADOPCIÓN EN LA ASAMBLEA NACIONAL CONSTITUYENTE. III. LAS COMPETENCIAS ATÍPICAS DEL CONTROL CONSTITUCIONAL EN LA JURISPRUDENCIA DE LA CORTE. IV. LAS COMPETENCIAS ADICIONALES, ADJUNTAS O ATÍPICAS AL CONTROL CONSTITUCIONAL EN EL DERECHO COMPARADO. V. DECISIONES DE LA CORTE CONSTITUCIONAL SOBRE EXCUSAS. 1. NATURALEZA JURÍDICA. 2. DECISIONES. VI. CONCLUSIONES. BIBLIOGRAFÍA. 


\title{
FUNCIONES SECUNDARIAS DE LA CORTE CONSTITUCIONAL COLOMBIANA: UNA APROXIMACIÓN A LA DECISIÓN SOBRE EXCUSAS A LOS EMPLAZAMIENTOS CURSADOS POR EL CONGRESO
}

\author{
RODRIGO GONZÁLEZ QUINTERO ${ }^{1}$ \\ LUIS JAVIER MORENO ORTIZ ${ }^{2}$
}

\section{INTRODUCCIÓN}

El establecimiento de tribunales constitucionales parece ser práctica requerida en diversas partes del mundo, y su función paradigmática radica en el control constitucional; en virtud de éste, examinan —y deciden sobre la validez de— legislación, tratados internacionales y actividad administrativa. Por ello, no extraña que en el Derecho Constitucional Comparado los estudios académicos se hayan dirigido a la función de control constitucional, como principal, dejando a un lado otras funciones que podrían calificarse como secundarias o adjuntas. Sin embargo, el entendimiento institucional completo de estos tribunales, exige referenciar dichas funciones secundarias que se alejan de la esencia de los procedimientos constitucionales. ${ }^{3}$

\footnotetext{
${ }^{1}$ Rodrigo González Quintero. Universidad Sergio Arboleda. Calle 74 n. ${ }^{\circ}$ 14-14. Bogotá D.C., COLOMBIA. Doctor en Derecho (J.S.D.) Washington University in St. Louis. Director del Departamento de Derecho Público y Profesor-Investigador de la Universidad Sergio Arboleda. Email: rodrigo. gonzalez@usa.edu.co,rgonqui@gmail.com

${ }^{2}$ Luis Javier Moreno Ortiz. Universidad Sergio Arboleda. Calle 74 n. ${ }^{\circ}$ 14-14. Bogotá D.C., COLOMBIA. Ph.D. Universidad Sergio Arboleda, Profesor de las Universidades Sergio Arboleda, Pontificia Javeriana y De La Sabana. Director del Instituto de Estudios Constitucionales de la Escuela de Derecho de la Universidad Sergio Arboleda. Email: luis.morenoj@usa.edu.co

3 Tom Ginsburg y Zachary Elkins, «Ancillary Powers of Constitutional Courts», Texas Law Review, Vol. 87, 2008-2009, pp. 1431-1432.
} 
Como órgano de cierre en una jurisdicción constitucional calificada como de las más amplias y accesibles del mundo, ${ }^{4}$ la Corte Constitucional de Colombia - establecida en el año 1991 - vela por la guarda de la integridad y supremacía de la Constitución. ${ }^{5}$ Así, mientras los estudios acerca de las atribuciones de la Corte sobre control constitucional abstracto y revisión de acciones de tutela han sido prolíficos, el interés sobre otras de sus funciones secundarias — como la la iniciativa legislativa en materias que le competen, la electiva de un miembro del Consejo Superior de la Judicatura, y la decisión sobre excusas de personas que desatiendan citaciones cursadas por el Congreso - ha sido escaso. En ese orden de ideas, el presente artículo se ocupa de uno de estos poderes adjuntos, la decisión final sobre excusas de personas que no asistan a citaciones de la legislatura.

La decisión final acerca de las excusas sobresale entre otras funciones que podrían denominarse como secundarias o adjuntas, ya que —al contrario de facultades electivas o de la iniciativa legislativa- ésta se expide mediante instrumentos procesales con efectos jurídicos claros, es decir autos; autos que, como se observará más adelante - cuentan con el rigor y la fuerza de la cosa juzgada constitucional. Ahora bien, es de advertir que la existencia de atribuciones secundarias para la Corte colombiana no es un fenómeno aislado dentro del constitucionalismo contemporáneo, sino que se enmarca en una tendencia similar presente en otras jurisdicciones constitucionales. Y advertir también que, como se expondrá en las páginas que siguen, la función de decidir las excusas ante el Congreso más que una atribución extra para ampliar los poderes de la Corte Constitucional, aparece como resultado lógico de la expansión del control político atribuido por el constituyente de 1991 al legislativo colombiano.

\section{APROXIMACIÓN AL SISTEMA DE CONTROL CONSTITUCIONAL EN COLOMBIA}

En la historia política y constitucional de Colombia, el control de constitucionalidad ha sido una presencia constante, aunque con manifestaciones diversas, en los poco más de dos siglos que tiene la República. En este período es posible vislumbrar tres épocas diferentes; la Primera República (1810-1816), la de los controles respecto de normas distintas a la ley (1853-1909) y la del control de constitucionalidad de las leyes (1910-2017). Cada etapa tiene sus particularidades y variables, aunque en todas se aprecia una constante, pues el ejercicio del control de constitucionalidad siempre ha tenido un rol protagónico un tribunal judicial.

En efecto, en la primera época este tribunal se denomina Senado; el de Censura en la Constitución de Cundinamarca de 1811, establecido en el artículo 4-Títu-

4 Manuel José Cepedda Espinosa, Polémicas Constitucionales, Bogotá, Legis, 2007, p. 42.

5 El artículo 241 de la Constitución de Colombia dispone que «A la Corte Constitucional se le confía la guarda de la integridad y supremacía de la Constitución.» 
lo VIII, cuya función es «velar sobre el cumplimiento exacto de [la] Constitución e impedir que se atropellen los derechos imprescriptibles del pueblo y del ciudadano», o Senado Conservador en la de Cartagena de 1812, prescrito en el artículo 9-Título II, cuya tarea es «sostener la Constitución, [y] reclamar sus infracciones». En la segunda época, al desarrollarse las competencias de las provincias en su mayor amplitud, según la fórmula de la Constitución de la República de la Nueva Granada de 1853, fue necesario diseñar un modelo de control del ejercicio de estas competencias, que estuvo a cargo de la Suprema Corte de la Nación (artículo 42.6 de la Constitución de 1853), de la Corte Suprema y del Senado (artículo 50 de la Constitución de 1858), de la Corte Suprema Federal y del Senado de Plenipotenciarios (artículo 72 de la Constitución de 1863) y de la Corte Suprema de Justicia (artículo 151.5 de la Constitución de 1886), vinculado al ejercicio de la acción pública de inconstitucionalidad. En la tercera época, que empieza con el Acto Legislativo ${ }^{6} 1$ de 2010 , el objeto del control se amplía para incluir leyes y normas de rango y jerarquía de leyes.

Es opinión generalizada el que uno de los aportes capitales de la Constitución de 1991 fue la creación de la Corte Constitucional, la cual tras más de veinticinco años de existencia es reputada como un órgano judicial robusto, que ha balanceado el ejercicio del poder público y afianzado la protección de los derechos humanos. ${ }^{7}$ Establecida en el Título VIII de la norma fundamental, el cual dispone del poder judicial, la Corte se enmarca dentro de los órganos que administran justicia; además de las disposiciones constitucionales que atañen su composición y competencias —artículos 239 al 245-, la regulación normativa se completa con mandatos contenidos en la Ley Estatutaria para la Administración de Justicia de 1996 y en los Decretos 2591 y 2067 de 1991.

La justicia constitucional colombiana se configura como «jurisdicción propia, separada y autónoma» ${ }^{8}$ de la cual la Corte es el órgano de cierre. Como sistema puede denominarse abstracto y concreto, concentrado y difuso, ex-ante y ex-post, y, ex-parte y ex-oficio. Es concentrado, abstracto, ex-post y ex-parte, en tanto que la Corte decide vía acción pública de inconstitucionalidad sobre reformas constitucionales - por vicios de forma-, leyes y decretos con fuerza de ley; los rasgos enumerados pero ex-oficio, pues la Corte decide la constitucionalidad de los decretos legislativos dictados bajo estados de excepción. Abstracto, ex-oficio y ex-ante, al decidir sobre proyectos de ley estatutaria, proyectos de ley objetados por el Gobierno, tratados internacionales y sus leyes aprobatorias, convocatorias a referendo y asamblea

${ }^{6}$ En la tradición constitucional colombiana se denomina como acto legislativo a una reforma constitucional realizada por el Congreso de la República; si bien podría calificarse como 'reforma a la constitución' o 'enmienda constitucional', el nombre técnico dado por el ordenamiento jurídico y por la doctrina es acto legislativo.

7 Rodrigo GonzÁlez Quintero, Pactos Constitucionales y Control Constitucional: Una Aproximación desde el Derecho Comparado, México D.F., Porrúa, 2017, p. 147.

8 Eduardo Cifuentes Muñoz, «La Justicia Constitucional en Colombia», en: Anuario Iberoamericano de Justicia Constitucional, No. 1, 1997, p. 3. 
constituyente; también cuando resuelve la constitucionalidad de referendos sobre leyes, consultas populares y plebiscitos nacionales. Es difuso y concreto, pues además de la Corte todos los jueces y tribunales de la República tienen potestad para resolver acciones de tutela, así como para apreciar la excepción de inconstitucionalidad; de otro lado, el Consejo de Estado — como órgano de cierre de la jurisdicción contencioso-administrativa - tiene facultad para conocer de la constitucionalidad de los decretos expedidos por el Gobierno cuyo control no sea competencia de la Corte Constitucional.

En diversas oportunidades la Corte ha hecho referencia al control constitucional en el sistema colombiano, cuyo propósito es «hacer efectivo el imperio del ordenamiento fundamental» ${ }^{9}$, identificando al menos tres elementos que lo hacen instrumento vital en la protección de la norma normarum. Como primer elemento, el surgimiento de la justicia constitucional a partir de «la necesidad de controlar y limitar el ejercicio del poder político en beneficio de la normatividad de la Constitución», así como también para proteger los derechos contenidos en ella en cuanto fundamento «de toda comunidad organizada, de la paz, de la convivencia pacífica y de la justicia.» ${ }^{10}$ Como segundo elemento, la justicia constitucional es resultado de la evolución socio-política en una democracia consolidada, y a través de tal jurisdicción se conforma «un sistema de defensa de la Constitución, impidiendo que la violación directa de la misma o el desconocimiento de sus reglas pase inadvertido.» En suma es «consecuencia necesaria y obvia del carácter normativo de la Carta, [la cual es] pilar fundamental del proceso político y de la vida social.» $\mathrm{Y}$ un tercer elemento descansa en que la justicia constitucional se establece «para asegurar el respeto de las normas básicas constitucionales, tanto las orgánicas como las dogmáticas.» ${ }^{11}$

Una de las variantes de mayor interés en la última época, más allá de la importante novedad que implica la existencia de controles automáticos, es la existencia de controles de constitucionalidad al ejercicio de funciones distintas a la legislativa o a la de reforma a la Constitución. Tal es el caso del control de constitucionalidad al ejercicio de la función judicial, que se hace por medio de la acción de tutela contra providencias judiciales y contra actuaciones judiciales, del control de constitucionalidad al ejercicio de la función administrativa, que también puede hacerse por medio de la acción de tutela, sin perjuicio de las eventuales actuaciones administrativas y acciones contencioso administrativas, e incluso del control de constitucionalidad sobre el ejercicio de funciones como la de control político o público por el Congreso, hipótesis en la que puede centrarse la competencia para definir la validez o no de las excusas dadas por quienes no comparecen al emplazamiento que les hace las comisiones permanentes de cualquiera de las cámaras.

\footnotetext{
9 Corte Constitucional de Colombia, Sentencia C-600/98, fundamento jurídico 3.

${ }^{10}$ Corte Constitucional de Colombia, Auto 010/04, fundamento jurídico 2.1.1.

11 Ibidem, fundamentos jurídicos 2.1.1 y 2.1.2.
} 
Ahora bien, como adicionales a las competencias enmarcadas dentro de la garantía jurisdiccional de la Constitución, la Corte colombiana tiene potestad para elegir un miembro del Consejo Superior de la Judicatura y decidir sobre las excusas de personas que desatienden las citaciones cursadas por el Congreso de la República. Estas competencias pueden denominarse como secundarias, adjuntas y atípicas, con relación a aquellas que comprenden el núcleo del sistema de justicia constitucional.

Doctrinalmente —especialmente autores españoles como el profesor García-Pelayo — se ha discutido la pureza de la jurisdicción constitucional; así, tanto en España como en Alemania se ha entendido que los rasgos definitorios de un tribunal constitucional son el ser establecidos por la Constitución directamente y su atribución de jurisdicción. Es decir, es 'órgano fundamental' en cuanto recibe «directamente de la Constitución su status y competencias esenciales a través de cuyo ejercicio se actualiza el orden jurídico político fundamental.» ${ }^{12}$ Dado que la justicia constitucional, como garantía de la supremacía de la Constitución, se configura en en la primacía de ésta «con respecto a la ley y a otras decisiones de los poderes públicos» ${ }^{13}$, para el caso colombiano la citación del Congreso a cualquier persona habrá de sujetarse a la Constitución; y a la verificación de tal sujeción que realice la Corte Constitucional.

Aunque es problemático — según García-Pelayo— «la posibilidad de establecer un concepto claro y distinto de jurisdicción constitucional en sentido material», se puede no obstante entender que «pertencen a la materia de jurisdicción constitucional los problemas relativos a la determinación del área del poder estatal y al sistema de derechos fundamentales.» ${ }^{14} \mathrm{Si}$ se entiende que es parte de la jurisdicción constitucional aquella labor del tribunal cuando «juzga siempre sobre la constitucionalidad de los actos de los órganos del Estado», ${ }^{15}$ entonces la función de la Corte colombiana que se estudia en éste artículo sería 'materialmente pura' en tanto consiste en juzgar la constitucionalidad del actuar del Congreso cuando emplaza a personas. Y si bien hace parte material de la jurisdicción constitucional, también puede denominarse como 'adjunta' o 'secundaria' pues se encamina a proteger derechos fundamentales por fuera del mecanismo constitucional por excelencia, la acción de tutela. ${ }^{16}$

12 Manuel García-Pelayo, «El Status del Tribunal Constitucional», Revista Española de Derecho Constitucional, No. 100, 2014, pp. 15-17.

13 Ibidem, p. 22.

${ }_{14}$ Ibidem, p. 35.

${ }^{15}$ Ibidem, p. 35.

${ }^{16}$ Mecanismo judicial preferente, expedito e informal —establecido en el artículo 86 de la Constitución Política de Colombia - mediante el cual toda persona puede reclamar ante cualquier juez, la protección de sus derechos fundamentales. 


\section{COMPETENCIAS ADICIONALES, ADJUNTAS O ATÍPICAS AL CONTROL CONSTITUCIONAL: DISCUSIÓN Y ADOPCIÓN EN LA ASAMBLEA NACIONAL CONSTITUYENTE}

La labor de hacer una nueva Constitución, en poco menos de un semestre ${ }^{17}$, implicó para el órgano responsable de ella: la Asamblea Nacional Constituyente, adoptar un método de división del trabajo en comisiones (conformadas por el artículo 23 del Reglamento de la Asamblea) ${ }^{18}$ y en subcomisiones, y la necesidad de introducir cambios sucesivos conforme se avanzara en el trabajo de las mismas. Esta metodología de trabajo hace que los textos normativos, en especial los nuevos, tenga un correlato fundamental entre sí, al punto de que sin tener presente este correlato serían incomprensibles tanto en su texto como en el contexto en el que surgen y al cual están destinados a regir.

Las competencias adicionales, adjuntas o atípicas al control de constitucionalidad, que la Carta de 1991 atribuye a la Corte Constitucional, no pueden comprenderse sólo a partir del estudio de lo acaecido en el seno de la Comisión Cuarta ${ }^{19}$ de la Asamblea Nacional Constituyente, dedicada a la Administración de Justicia y al Ministerio Público, sino que se requiere considerar, en la medida en que ahí reside la causa que las justifica, los debates de la Comisión Tercera $^{20}$ de la misma, responsable de las reformas a la estructura del Estado, el Congreso, la fuerza pública, el régimen de estado de sitio y las relaciones internacionales.

Conforme a un orden lógico, corresponde entonces ocuparse primero de la nueva competencia del Congreso, que es, a su vez, la causa o correlato de la competencia

17 La Asamblea Nacional Constituyente se instaló en Bogotá el 5 de febrero de 1991 y sus trabajos culminaron con la promulgación de la Constitución el 4 de julio de 1991. En estos cinco meses, su órgano de divulgación oficial: la Gaceta Constitucional, tuvo 144 números. En la Biblioteca Luis Ángel Arango del Banco de la República, se encuentra el archivo de la Asamblea, con soporte en documentos impresos, audio y video (http://babel.banrepcultural.org/cdm/landingpage/collection/p17054coll28)

18 Este artículo dispone que la Asamblea tendrá cinco comisiones permanentes y asigna sus respectivas competencias de la siguiente manera: Comisión Primera. Principios, derechos, deberes, garantías y libertades fundamentales. Mecanismos e instituciones de protección. Participación democrática. Sistema electoral. Partidos políticos. Estatuto de la oposición. Mecanismos de reformas constitucionales. Comisión Segunda: Ordenamiento territorial del Estado. Autonomía regional y local. Comisión Tercera: Tercera. Gobierno y Congreso, fuerza pública, régimen de estado de sitio y relaciones internacionales. Comisión Cuarta: Administración de justicia y ministerio público. Comisión Quinta: Asuntos económicos. sociales y ecológicos.

19 Esta comisión estuvo integrada por ocho constituyentes, a saber: Carlos Daniel Abello Roca, Fernando Carrillo Flórez, Jaime Fajardo Landaeta, María Teresa Garcés Lloreda, Armando Holgín Sarria, Hernando Londoño Jiménez, Julio Salgado Vásquez y José María Velasco Guerrero.

20 Esta comisión estuvo integrada por quince constituyentes, a saber: Álvaro Echeverri Uruburu, Antonio Galán Sarmiento, Hernando Herrera Vergara, Carlos Lleras de la Fuente, Arturo Mejía Borda, Antonio Navarro Wolf, Luis Guillermo Nieto Roa, José Matías Ortiz Sarmiento, Rosemberg Pabón Pabón, Guillermo Plazas Alcid, Abel Rodríguez Cespedes, Miguel Santamaría Dávila, Alfredo Vázquez Carrizosa, Fabio Villa Rodríguez y Hernando Yepes Arcila. 
adicional, adjunta o atípica al control constitucional ${ }^{21}$. Esta competencia no guarda relación con la función legislativa ni con la de reformar la Constitución, sino que parece estar vinculada a la función de control político a cargo de este órgano. Consiste en la facultad que tiene cualquier comisión permanente del Senado o de la Cámara de Representantes para emplazar a cualquier persona, con el propósito de que rinda declaraciones orales o escritas en una sesión especial, incluso bajo la gravedad de juramento, respecto de hechos que guarden relación directa con las indagaciones que dicha comisión adelante (artículo $137 \mathrm{CP}$ ). El régimen legal para el ejercicio de esta competencia está fijado en el artículo 236 de la Ley Orgánica del Reglamento del Congreso (Ley 5 de 1992) ${ }^{22}$.

En ese sentido, podría afirmarse que la competencia atribuida a las comisiones permanentes de ambas cámaras es nueva, en la medida en que en el referente constitucional anterior - la Constitución de 1886 y sus reformas - si bien trata la competencia de control político lo hace en términos mucho más estrictos y reducidos. En efecto, el artículo 103.6 del texto original de dicha Constitución, faculta a cada cámara para pedir a los Ministros los informes orales o escritos que necesite para el desempeño de sus trabajos o para conocer los actos de la Administración, con la restricción del artículo 78.4 ibídem, es decir, siempre y cuando no se trate de instrucciones a Ministros diplomáticos o de negociaciones que tengan carácter reservado.

Esta norma constitucional será objeto de dos reformas, en los años 1968 y 1979; la primera de ellas (AL 1 de 1968, artículo 30) modifica las competencias de cada cámara agregando un inciso final, en el cual precisa el modo de hacer la citación a los Ministros — con no menos de 48 horas de anticipación y por medio de cuestionario escrito- estableciendo la obligación de concurrir que tienen éstos y fijando el alcance del debate, al señalar que no puede extenderse a asuntos ajenos al cuestionario. La segunda de ellas (AL 1 de 1979, artículo 23) mantiene el ordinal en comento aunque lo vincula a la función de control político y redacta de manera más minuciosa el referido inciso final. Vínculo con la función de control político, logrado al adicionar un inciso al artículo 76 de la Constitución, y define las cuatro competencias principales del Congreso — reformar la Constitución, hacer las leyes, ejercer el control político y administrar justicia- Aparece además una novedad relevante, la moción de observaciones, que si bien no es una moción de censura, permite a las cámaras «formular las observaciones del caso mediante proposición aprobada por las dos terceras partes de los votos de los asistentes».

21 Lo atípico o adicional de la competencia se predica de su materia y objeto, no de su reconocimiento expreso por la Constitución, en el artículo 241.6, valga decir, en este punto no se sigue la distinción que hace la propia Corte Constitucional entre sus competencias típicas y atípicas, pues ésta se funda en dicho reconocimiento.

22 Este artículo hace parte de la sección relativa a citaciones en general y aparece bajo el título «Citación a particulares», lo que explicará más adelante la recurrente preocupación de la Corte Constitucional por determinar el tipo de citación y sus consecuencias. 
En la Constitución de 1991 y en la reforma introducida a ésta por medio del Acto Legislativo 1 de $2007^{23}$, la función del control político se fortalecerá por medio de nuevas competencias e instituciones, como se tuvo la oportunidad de destacar en un estudio anterior ${ }^{24}$. Si bien se mantiene grosso modo las competencias de las cámaras del antiguo artículo 103 y la prohibición del añejo artículo 78, en los artículos 135 y 136 de la nueva Carta, respectivamente, se introduce una importante novedad respecto de unas y otra: la ampliación de las personas que pueden ser citadas, que de Ministros pasa también a Superintendentes y Directores de Departamentos Administrativos y, lo que es más importante, la moción de observación se torna ahora moción de censura, que al tenor de la reforma de 2007, puede ser propuesta por cualquiera de las cámaras (por la décima parte de sus miembros) y aprobada por la mitad más uno de sus integrantes. Este control y la posibilidad de la censura se extienden a los cuerpos de elección popular de los departamentos, municipios y distritos, respecto de autoridades de dichos territorios.

Además de estos cambios aparece una norma que antes no existía, el aludido artículo 137 que es, justamente, la que origina o causa la también nueva competencia de la Corte Constitucional de resolver sobre las excusas que las personas emplazadas dieren a las susodichas comisiones, si éstas insistieren en su llamado (art. 137, inc. 2, en concordancia con el art. 241.6), cuyo régimen legal y reglamentario, está dado por el artículo 47 del Decreto 2067 de 1991 (por el cual se dicta el régimen procedimental de los juicios y actuaciones que deban surtirse ante la Corte Constitucional) y por los artículos 75 a 80 del Reglamento de la Corte Constitucional (Acuerdo 02 del 22 de julio de 2015).

La relación entre la nueva competencia y la función de control político, además de evidente en el anterior análisis, fue reconocida de manera explícita por los propios constituyentes en la Comisión Tercera, ${ }^{25}$ sobre la función de control político del Congreso. En este documento se presenta el que a la postre será el artículo 137, con la única diferencia que la competencia para determinar si las excusas son o no válidas, se atribuye a la Sala Constitucional de la Corte Suprema de Justicia. Los motivos de

${ }^{23}$ Este acto, «Por medio del cual se modifican los numerales 8 y 9 del artículo 135 , se modifican los artículos 299 y 312, y se adicionan dos numerales a los artículos 300 y 313 de la Constitución Política», profundiza el control político, al reconocer en los órganos representativos locales: asambleas y concejos, como corporaciones político-administrativas, esto es, como entes capaces de ejercer la función de control político en el ámbito de sus respectivos territorios. Por ello, como se verá más adelante, una de las dificultades al momento de considerar las excusas está dada por el alcance de la materia que se somete a control político, pues de esto depende si dicho control corresponde a las comisiones permanentes del Congreso (alcance nacional) o a las asambleas y los concejos (alcance meramente local).

${ }^{24}$ Luis Javier Moreno OrTIZ, «La moción de censura en Colombia: historia de una heterodoxia», en: Revista del Instituto de Estudios Constitucionales de la Universidad Sergio Arboleda, Núm. 12, 2008, pp. 7-77.

25 Alfonso Palacio Rudas, «Ponencia sobre la función de control político del Congreso», 1991, Disponible en: http://babel.banrepcultural.org/cdm/singleitem/collection/p17054coll28/id/344/rec/1. 
la propuesta, en cuanto atañe a este artículo, se sintetizan en al final del documento, en los siguientes términos:

Como de la investigación se puede desprender la necesidad de que intervengan otras autoridades ya sea para desarrollar las conclusiones de la Comisión o para la persecución de posibles infracciones penales, se autorizó a las comisiones para excitar a dichas autoridades ${ }^{26}$.

La mención de la Sala Constitucional de la Corte Suprema de Justicia no es un error ni una casualidad, pues al momento de darse el antedicho debate en la Comisión Tercera, en la Cuarta se libraba una interesante controversia en torno a qué órgano debe ser el responsable principal de ejercer el control de constitucionalidad. La mayoría ${ }^{27}$ proponía la creación de una Corte Constitucional, mientras que otros liderados por el constituyente José María Velasco Guerrero ${ }^{28}$ — quien había sido Magistrado de la Corte Suprema de Justicia y ponente de una importante sentencia del año 1978 en la que se había declarado inexequible un acto reformatorio de la Constitución ${ }^{29}$ defendían el mantener dicho control en manos de la Corte Suprema de Justicia.

El sonado debate sobre el órgano, visible en todas las ponencias relativas a esta materia y en un informe de la minoría ${ }^{30}$, no debe llevar a pensar que había también un clima igual respecto de las funciones de dicho órgano. En efecto, al momento de ocuparse de dichas funciones, se aprecian dos líneas de acción bien definidas; la primera era la de mantener la dualidad orgánica en materia de control concentrado de constitucionalidad, sea entre el Consejo de Estado y la Corte Constitucional o entre este y la Corte Suprema de Justicia, como había sido y todavía es la tradición de la República desde la segunda década del siglo xx. Y la segunda era la de ampliar las competencias de control de constitucionalidad de la Corte Constitucional o Corte Suprema de Justicia - tanto en su objeto como en su ejercicio- para incluir, por ejemplo, tratados internacionales y regular diversas modalidades de control que puede ejercerse sin necesidad de intervención alguna de un órgano o persona ajeno al tribunal. Es decir, ésta última línea propendía hacia un control automático.

En cuanto atañe al objeto de este artículo, conviene destacar que la competencia relativa a las excusas no fue materia de los trabajos iniciales de la Comisión Cuarta y

26 Ibidem, pp.11-12.

27 María Teresa Garcés LloredA, «De la Administración de Justicia», 1991, Disponible en: http:// babel.banrepcultural.org/cdm/ref/collection/p17054coll28/id/341

28 José María Velasco Guerrero, "Informe presentado por José María Velasco Guerrero sobre Consejo de Estado, Corte Suprema de Justicia y control jurisdiccional de constitucionalidad», 1991, Disponible en: http:// babel.banrepcultural.org/cdm/ref/collection/p17054coll28/id/295

29 Por medio de Sentencia del 5 de mayo de 1978 (Gaceta Judicial 2397, pp. 91-126), la Sala Plena de la Corte Suprema de Justicia declaró inexequible el Acto Legislativo 2 de 1997, por medio del cual se modificaba la Constitución, al «no haberse ajustado en su formación al artículo 218 y a sus complementos constitucionales, con excepción de su artículo 14 que se declara EXEQUIBLE».

30 Armando Holguín Sarria y Carlos Daniel Abello Roca, «Informe de minoría», 1991, Disponible en: http://babel.banrepcultural.org/cdm/ref/collection/p17054coll28/id/290 
que apenas vino a estudiarse cuando se había madurado la idea de replantear la función de control político en la Comisión Tercera; algunos autores ${ }^{31}$ afirman que la competencia en cuestión no aparecía atribuida a la Corte Constitucional en el texto aprobado por la Asamblea Nacional Constituyente en primer debate, sino que dicho texto fue incluido más tarde por la Comisión Codificadora, ${ }^{32}$ argumentando que «se trata[ba] de una protección de los derechos fundamentales del individuo frente a un órgano del Estado» ${ }^{33}$. La amplitud de la función conferida a las comisiones de las Cámaras fue criticada por algunos constituyentes; tanto que al ocuparse de la competencia correlativa de la Corte Constitucional afirmaban que ésta «no es una función propia del órgano de control constitucional, sino más bien una función de naturaleza judicial que mejor hubiera quedado en cabeza del Consejo de Estado.» ${ }^{34}$

\section{LAS COMPETENCIAS ATÍPICAS DEL CONTROL CONSTITUCIONAL EN LA JURISPRUDENCIA DE LA CORTE}

Existen entonces competencias secundarias o adjuntas a las del control constitucional, las cuales están enunciadas en la Constitución, así como otras que se encaminan a la garantía jurisdiccional de la misma pero que al no estar prescritas en la norma fundamental han sido denominadas por la Corte como atípicas.

Así, éstas últimas competencias surgen a partir de casos atípicos de control constitucional, en cuanto funciones especiales «cuya fijación es solo posible a través del empleo de criterios formales y materiales desarrollados jurisprudencialmente.» ${ }^{35}$ En ese orden de ideas para el alto tribunal es posible acometer «el juzgamiento de actos y decretos diferentes [y especiales],en atención a ciertas características de la norma, [y] pese a no existir una competencia expresamente atribuida por la Carta.» ${ }^{36}$ En sus decisiones la Corte ha identificado varios eventos en los que dichas competencias son ejercitadas, dentro de los que podrían destacarse los siguientes casos. Un primer evento es el control de los Decretos con Fuerza de Ley expedidos con anterioridad a la Constitución de 1991; si bien han sido expedidos en desarrollo de facultades extraordinarias al amparo de la Constitución de 1886 derogada, la Corte ha ejercido control sobre ellos en cuanto actos con fuerza de ley, así como

31 Carlos Lleras de la Fuente, Carlos Adolfo Arenas Campos, Juan Manuel Charry Urueña y Augusto Hernández BeCErra, Interpretación y Génesis de la Constitución de Colombia, Bogotá, Cámara de Comercio de Bogotá, 1992.

32 Dado que uno de los autores, Carlos Lleras de la Fuente, no sólo fue miembro de la Asamblea Nacional Constituyente, sino que también lo fue de su comisión codificadora, se trata de la afirmación de un testigo directo, e incluso protagonista, de los hechos.

33 Carlos Lleras de la Fuente, Carlos Adolfo Arenas Campos, Juan Manuel Charry Urueña y Augusto Hernández Becerra, Interpretación y Génesis de la Constitución de Colombia, Op. cit., p. 420.

34 Ibidem, 274.

35 Corte Constitucional de Colombia, Sentencia C-049/12, fundamento jurídico 3.2.2.

36 Corte Constitucional de Colombia, Sentencia C-173/14, fundamento jurídico 1.3.1. 
extendiendo el concepto de control sobre ley en sentido material. ${ }^{37}$ Un segundo evento es la revisión de Decretos compilatorios de leyes, en tanto que tienen un contenido material de ley. ${ }^{38}$

Un tercer evento surge a partir de los Decretos que declaran un estado de excepción, atípicos pues materialmente no contienen normas suspensivas o derogatorias de leyes; ahora bien, la Corte ha confirmado el conocimiento sobre ellos, acudiendo a funciones desempeñadas por la Corte Suprema de Justicia bajo el régimen de 1886, declarando que «no existen actos políticos o de poder exentos de control constitucional, menos tratándose de un acto presidencial de autohabilitación legislativa.» ${ }^{39}$ Un cuarto evento se da con los Decretos expedidos por habilitación de Disposiciones transitorias de la Constitución, pues la Corte ha entendido que estos son verdaderos actos con fuerza de ley y de naturaleza legislativa, surgidos de facultades legislativas extraordinarias. ${ }^{40}$ Un quinto evento es la revisión de los Decretos que corrigen yerros en normas de carácter legal, puesto que «cuando se declara la inconstitucionalidad de una disposición legal corregida por el decreto de yerros, surge una inconstitucionalidad por consecuencia de éste y, así, la competencia de la Corte para declararlo.» ${ }^{41} \mathrm{Y}$ un sexto evento surge con el control de Decretos que convocan a sesiones extraordinarias al Congreso, dado que la Corte tiene competencia para decidir sobre la oportunidad de la la convocatoria y la vigencia del decreto; además, si bien el decreto es acto administrativo en este caso hace parte del proceso legislativo y de la validez de las sesiones extras. ${ }^{42}$

\section{LAS COMPETENCIAS ADICIONALES, ADJUNTAS O ATÍPICAS AL CONTROL CONSTITUCIONAL EN EL DERECHO COMPARADO}

Tribunales Constitucionales especializados se han expandido en el mundo durante las últimas décadas; así, el modelo concebido originalmente por Kelsen para la Constitución austriaca de 1920, fue luego adoptado en la Alemania de la postguerra y expandido en olas democratizadoras a otras partes del globo. Si bien el modelo kelseniano propugna por un tribunal que opera como legislador negativo — es decir, uno que tiene potestad para invalidar legislación pero no para proponerla-, la tendencia general ha sido expandir las competencias del mismo más allá de éste rol. ${ }^{43}$

37 Corte Constitucional de Colombia, Sentencia C-049/12, fundamento jurídico 4.1.2.

38 Ibidem, fundamento jurídico 4.2.2.

39 Ibidem, fundamentos jurídicos 4.3.1 y 4.3.2.

40 Ibidem, fundamento jurídico 4.4.2.

41 Ibidem, fundamento jurídico 4.5.2.

42 Ibidem, fundamento jurídico 4.10.

43 Nuno Garoupa, y Tom Ginsburg, «Building Reputation in Constitutional Courts: Political and Judicial Audiences», Arizona Journal of International and Comparative Law, Vol. 28, No. 3, 2011, pp. 539-540. 
Las dos funciones o atribuciones principales que se adscriben al control constitucional son la revisión judicial de las leyes - y por extensión de tratados internacionales y decretos - y la protección de derechos fundamentales, las cuales están cobijadas por el texto de la Constitución. Otras funciones asignadas a los tribunales constitucionales incluyen el proponer legislación, determinar la constitucionalidad de los partidos políticos, certificar estados de excepción, juzgar altos funcionarios, y decidir controversias electorales. ${ }^{44}$

Parecería básico afirmar que el trabajo del juez es decidir casos, aunque en muchas jurisdicciones también se le asignan otras funciones no judiciales; el rango de éstas va desde tomar parte en comisiones intersectoriales hasta desempeñarse como jefe de gobierno encargado. Y son precisamente los rasgos que se atribuyen a la labor del juez - entre otros independencia, imparcialidad y no militancia política- lo que hacen ser deseado en funciones no judiciales. A manera de ejemplo de tales funciones pueden reseñarse funciones en tribunales electorales, control de partidos políticos, y, elección de otros jueces. ${ }^{45}$

No obstante, fuera de las atribuciones no paradigmáticas enunciadas existen algunas más extremas; por ejemplo el Tribunal Constitucional de Bielorrusia tuvo hasta el año 1996 atribución para proponer reformas constitucionales, y el de Portugal debe certificar la incapacidad o muerte del presidente. El espectro de los poderes secundarios o adjuntos comprende un espectro amplio, aunque podrían clasificarse en aquellos cuya naturaleza es eminentemente jurídica - como proponer legislación o determinar la constitucionalidad de partidos - y aquellos cuya naturaleza es política — como el juicio de funcionarios o la decisión de controversias electorales_- ${ }^{46}$

Distintos sistemas se configuran como ejemplos de las funciones secundarias o adjuntas mencionadas; así, el Tribunal Constitucional austriaco tiene varias de éstas atribuciones entre las que pueden destacarse el control de elecciones, la decisión sobre conflictos de competencia — judiciales, entre länders, o entre länders y la federación-, y los juicios de altos funcionarios. ${ }^{47}$ En Francia, el Consejo Constitucional cuenta con potestad para definir la legalidad de las elecciones presidenciales y parlamentarias, así como sobre los resultados de referéndums y las incompatibilidades de miembros del parlamento. ${ }^{48}$ Para el caso alemán, el Tribunal Constitucional es el único órgano

44 Tom Ginsburg y Zachary Elkins, «Ancillary Powers of Constitutional Courts», Op. cit., pp. 1434-1441.

${ }^{4}$ Nuno Garoupa, y Tom Ginsburg, «Judicial Roles in Nonjudicial Functions», Washington University Global Studies Law Review, Vol. 12, 2013, pp. 756-760.

46 Tom Ginsburg y Zachary Elkins, «Ancillary Powers of Constitutional Courts», Op. cit., pp. 1441-1443.

47 Anna Gamper y Francesco Palermo, «The Constitutional Court of Austria: Modern Profiles of an Archetype of Constitutional Review», en: Andrew Harding y Peter Leyland (eds.), Constitutional Courts: A Comparative Study. London, Wildy, Simmons \& Hill, 2009, pp. 31-43.

48 Marie Ponthoreau y Fabrice Hourquebie, «The French Conseil Constitutionnel: An Evolving Form of Constitutional Justice», en: Andrew Harding y Peter Leyland (eds.), Constitutional Courts: A Comparative Study. London, Wildy, Simmons \& Hill, 2009, pp. 81-89. 
con poder para declarar como inconstitucional a un partido político, cuando éste amenace el orden democrático o la existencia de la república federal. También resuelve conflictos competenciales entre los órganos federales, y entre éstos y los länder. ${ }^{49}$ En Italia, el Tribunal Constitucional cuenta con atribución para juzgar al Presidente de la República, así como para admitir o no referéndums contra leyes; decide además los conflictos de competencia surgidos entre órganos estatales, entre el Estado y las regiones y entre regiones. ${ }^{50}$

\section{DECISIONES DE LA CORTE CONSTITUCIONAL SOBRE EXCUSAS}

\section{Naturaleza jurídica}

La competencia de la Corte Constitucional para decidir sobre las excusas de que trata el artículo 137 de la Carta, prevista en el artículo 241.6 ibídem, guarda relación con la competencia atribuida por aquél a las comisiones de ambas cámaras, en ejercicio de la función de control político, para emplazar a cualquier persona con el propósito de que rinda declaraciones sobre hechos que tengan relación directa con las indagaciones que tales comisiones adelanten.

En vista de las dos antedichas competencias: la primera propia de la función de control político a cargo del Congreso y la segunda relativa al ejercicio de la primera a cargo de la Corte Constitucional, podría decirse que esta última es, en lo orgánico, un control jurisdiccional al Congreso y, en lo funcional, un control judicial al ejercicio de actos propios del control político, que puede calificarse en términos de «una protección de los derechos fundamentales del individuo frente a un órgano del Estado» ${ }^{51}$. En tanto se puede considerar como un mecanismo de protección de derechos, esta competencia jurisdiccional estaría más próxima a otros mecanismos previstos en la Carta, como la acción de tutela y, por tanto, podría hallar cobijo dentro de las competencias de control de constitucionalidad de los actos no normativos del Congreso y, en esa media, considerarse como una competencia propia del control de constitucionalidad aunque con ciertas particularidades.

Si bien la competencia podría enmarcarse en la protección de los derechos fundamentales, aunque la función es jurisdiccional no parece ser propia del control de

49 Donald Kommers y Russell Miller, «Das Bundesverfassunggsgericht: Procedure, Practice and Policiy of the German Federal Constitutional Court», en: Andrew Harding y Peter Leyland (eds.), Constitutional Courts: A Comparative Study. London, Wildy, Simmons \& Hill, 2009, pp. 102-112.

50 Tania GroppI, «The Italian Constitutional Court: Towards a Multilevel System of Constitutional Review», en: Andrew Harding y Peter Leyland (eds.), Constitutional Courts: A Comparative Study. London, Wildy, Simmons \& Hill, 2009, p. 127.

${ }^{51}$ Carlos Lleras de la Fuente, Carlos Adolfo Arenas Campos, Juan Manuel Charry Urueña y Augusto Hernández Becerra, Interpretación y Génesis de la Constitución de Colombia, Op. cit., p. 420. 
constitucionalidad, sino de otro tipo de actividad judicial; una más cercana a la que podría corresponder al Consejo de Estado, como una especie de tribunal de garantías en el proceso de control político.

Ante las dos posibles hipótesis sobre la naturaleza jurídica de la competencia de la Corte Constitucional, parece aconsejable consultar el desarrollo normativo de la misma, tanto en la Ley 5 de 1992, orgánica del reglamento del Congreso, como en el Decreto 2067 de 1991 y el Acuerdo 2 de 2015, que regulan las actuaciones ante dicho tribunal.

La primera, en su artículo 236, desarrolla el artículo 137 de la Constitución, a partir de tres reglas relevantes, no incluidas en la norma constitucional, a saber: (i) toda pregunta debe absolverse, salvo las restricciones constitucionales o legales, so pena de incurrir en desacato a la autoridad; (ii) cualquier congresista puede solicitar a la comisión competente adelantar la indagación que considere corresponda; (iii) la competencia de las comisiones se determina por la materia de sus competencias legislativas, correspondiendo a la Comisión Primera las indagaciones cuya materia no esté asignada de manera expresa por la ley a ninguna comisión.

El segundo, en su artículo 47, prevé que corresponde al presidente de la respectiva comisión, cuando esta insista en llamar a quién se ha excusado, informar a la Corte Constitucional sobre la renuencia e indicar el nombre del citado y el motivo de la citación. Al recibir este informe, el tribunal debe proceder a convocar una audiencia privada para oír al citado y definir si su excusa es o no fundada, dentro de los seis días siguientes a dicha recepción.

El tercero, en sus artículos 75 a 80, dispone que el asunto se someterá al trámite ordinario para su reparto (por orden alfabético y al azar); que la citación a la persona que se excusa debe hacerse dentro de los cinco días siguientes al reparto; que la convocatoria a audiencia privada ante la Sala Plena debe ser hecha por su Presidente el día señalado por el magistrado sustanciador; que el proyecto de decisión debe registrarse dentro de los cinco días siguientes a la finalización de la audiencia; que la decisión la tomará la Sala Plena dentro de los diez días siguientes al registro, bajo estricta reserva; y que copia de esta decisión será remitida por la secretaría general del tribunal al presidente de la respectiva comisión del Congreso.

$\mathrm{El}$ análisis de los anteriores referentes normativos permite confirmar el punto de consenso entre las dos hipótesis en cuestión, en el sentido de que se trata de una competencia jurisdiccional, tanto por el órgano que la ejerce, como por su contenido, al punto de que su ejercicio corresponde a la Sala Plena de un tribunal de justicia y se concreta en una providencia judicial.

En cuanto a la divergencia entre las hipótesis, valga decir, si es una competencia jurisdiccional que corresponde al control de constitucionalidad o una competencia atípica o agregada a éste, la situación no parece tan clara, pues esto depende, en rigor, del fundamento de la excusa y de la insistencia de la comisión del Congreso. Así, pues, si la excusa se basa en un derecho fundamental y, por tanto, la decisión sobre si ésta está se ocupa de su protección, parecería que es más verosímil considerar que sí se 
trata de una competencia propia del control de constitucionalidad. Empero, al admitirse también razones legales para fundar la excusa, puede considerarse, al menos ab initio, como razonable pensar que, al menos en este evento, sería una competencia atípica o agregada. Lo cierto es que esta controversia no puede definirse a partir de un análisis meramente teórico y normativo, sino que reclama un examen empírico de los casos estudiados por el tribunal y, con ello, tanto de sus consideraciones sobre la naturaleza de su competencia como de su ejercicio concreto.

\section{Decisiones}

La Corte Constitucional, en ejercicio de la competencia sub examine, tramita los casos de excusas bajo los expedientes E, de los cuales a la fecha se conocen 20 casos. La decisión de los mismos que, como se acaba de ver, corresponde a la Sala Plena del tribunal, se adopta por medio de autos. El análisis que se hace enseguida se ocupa de 19 expedientes, porque no fue posible encontrar los documentos relativos al primero de ellos en el archivo de la Corte Constitucional y su existencia se infiere a partir del que sí pudo encontrarse en primer término, que fue el Expediente E-002 y de la escueta mención que a él se hace en el Auto A-186 de 2004, cuando se alude al E-001 de 1992 y se menciona como su Magistrado Sustanciador a Eduardo Cifuentes Muñoz.

Primera década (1992-2002)

En el Auto 23 del 17 de septiembre de $1992^{52}$ se estudia la excusa que presentó la contadora de la Federación Nacional de Cafeteros, que para el efecto invocó su deber de guardar el secreto profesional, conforme al artículo 74 de la Constitución. El análisis del tribunal se centra en dos cuestiones: la pertinencia de la citación y el alcance de la garantía de inviolabilidad del secreto profesional. En la primera basa su declaración de que la excusa está fundada, pues conforme al artículo 236 de la Ley 5 de 1992, cuando la citación tiene por objeto conocer información propia de un ente jurídico, corresponde dirigirla al representante legal del mismo o a los miembros de su junta directiva y no a otro tipo de trabajadores de dicho ente, como es en este caso la contadora. En la segunda precisa que la garantía del secreto profesional, respecto de las comisiones del Congreso, sólo cubre aspectos que sean estrictamente privados de la federación, en tanto es una persona jurídica de derecho privado, pero de ningún modo lo relativo al Fondo Nacional del Café, que está conformado por recursos públicos.

El caso tratado en el Auto 006 del 20 de mayo de $1993^{53}$ involucra, además de la garantía del secreto profesional, la libertad de opinión de un periodista y la posible

52 Expediente E-002.

53 Expediente E-003. 
existencia de injurias y calumnias. La comisión, a instancias del congresista que se siente cuestionado por el periodista, cita a éste para que revele de qué modo obtuvo la información. En este caso el tribunal considera hacer una primera reflexión en torno la finalidad del artículo 137 de la Carta, que merece la pena tener en cuenta a fin de determinar cuál es la naturaleza de la competencia en cabeza de la Corte Constitucional. ${ }^{54}$ En esta reflexión se reconoce una evidencia y se hacen dos interpretaciones de la competencia: una amplia y otra restrictiva.

Lo que se reconoce como evidente es la razón de ser de la norma que es facultar al Congreso para allegar, por medio de este instrumento, elementos de juicio para desempeñar sus funciones, en especial la de control político.

La interpretación amplia se hace respecto del objeto de la competencia, en cuanto no puede entenderse limitada a lo que sea necesario para perfeccionar la investigación y perseguir posibles infractores penales, sino que debe ser más amplia, en el sentido de que «permita a las comisiones en el ejercicio de sus funciones propias y ordinarias, como la tramitación de los proyectos de ley, emplazar a personas naturales o jurídicas que puedan aportar conocimientos teóricos o experiencias directamente relacionadas con los trabajos del Congreso».

La interpretación restrictiva se predica tanto del declarar bajo juramento como de la relación que debe haber entre los hechos que sirven de base a las preguntas y las tareas que la comisión adelante. En cuanto a lo primero, se precisa que si bien se puede exigir el juramento, este no es obligatorio y, por tanto, es posible recibir declaraciones sin esta formalidad. En cuanto a lo segundo, se advierte que dicha relación debe ser directa, puesto que las preguntas deben ser pertinentes y no obedecer al mero «capricho» de la comisión o de sus integrantes.

Con base en los anteriores elementos de juicio, y previa alusión al secreto profesional del periodista y a la distinción entre información y opinión, la Sala declara fundada la excusa, dado que si bien se puede emplazar a periodistas esto debe hacerse conforme a la finalidad de la competencia, lo cual no ocurre en este caso (estándar de la relación directa) y, además, si el emplazamiento se hace por las opiniones expresadas, éste puede conllevar un modo de censura, «no por disimulada menos eficaz».

En el Auto del 10 de octubre de $1995,{ }^{55}$ al ocuparse de la excusa dada por el tesorero de la campaña política del que en ese momento fungía como Presidente de la República, que había sido cuestionada por su financiación por parte de recursos de origen ilícito, la Sala comienza por advertir que su competencia se extiende tanto a los emplazamientos que hagan las comisiones constitucionales permanentes como a otras comisiones de carácter legal, entre las que está la Comisión de Investigación y Acusación de la Cámara de Representantes, al interpretar en sentido amplio el enunciado «comisión permanente» previsto en la Carta, para superar la

54 Corte Constitucional de Colombia, Auto 006/93, fundamento jurídico 1.

55 Expediente E-004. 
restricción que la Ley 5 de 1992 parece establecer al referirse a comisiones constitucionales permanentes.

La excusa del tesorero se funda en tres razones principales: (i) su declaración, en la media en que afecta a muchas personas, que podrían ser vinculadas a un proceso penal, puede poner en riesgo su vida; (ii) el declarar ante la comisión puede afectar su proceso de colaboración eficaz ante la justicia y los beneficios que de ella se pueden desprender para su causa penal; y (iii) se podría vulnerar su derecho de defensa, en la media que podría incurrir en contradicciones, que pueden utilizarse en su contra, así como podría ser llevado a declarar en contra de sí mismo, a pesar de la garantía constitucional de no autoincriminación.

Luego de dejar en claro que la referida comisión legal sí tiene competencia para investigar y para acusar al Presidente de la República, al recordar que la Constitución «configura un gobierno de leyes por encima de las personas», el tribunal procede a estudiar la excusa y la declara infundada. Para llegar a esta conclusión, el tribunal argumenta que: (i) la mera circunstancia de declarar no tiene por qué poner en riesgo la vida del declarante y, si así lo hiciere, lo que procede no es validar la excusa del declarante, sino que las autoridades competentes le brinden la debida protección; (ii) el declarar ante la justicia no exime a la persona de la obligación de declarar también, como testigo, ante la comisión, respecto de hechos que guarden una relación directa con aquellos que ésta indaga, y declarar ante la comisión en nada afecta los beneficios del tesorero en el proceso penal que se le sigue, pues esto depende de lo que sobre el particular determine la Fiscalía; y (iii) el riesgo de incurrir en contradicciones es un argumento inaceptable, pues si se trata de los mismos hechos lo esperable es que el testigo responda con claridad, precisión y rigor, más aún cuando está de por medio la gravedad del juramento y, dado que la comisión no investiga al declarante sino al Presidente de la República, no se busca ni pretende que éste declare contra sí mismo, y si así ocurriere, es evidente que el declarante puede abstenerse de responder amparado en la garantía del artículo 33 de la Carta, según la cual nadie puede ser obligado a declarar contra sí mismo.

De esta decisión se apartará el Magistrado Vladimiro Naranjo Mesa, además de entender que no correspondía ni era necesario determinar si la comisión puede o no investigar al Presidente de la República, por considerar que sí podría haber afectación del debido proceso, en tanto y en cuanto al declarar ante la comisión estaría revelando públicamente lo que dijera ante la fiscalía en condiciones de reserva, pudiendo ser tenido lo que diga como una confesión, y lo haría sin la asistencia de un abogado, lo que afecta el principio de non bis in ídem y el derecho de defensa.

Por medio de Auto 080 del 14 de diciembre de $1998^{56}$ se revisa la excusa dada por el Alcalde Mayor de Bogotá D.C. para no comparecer ante la comisión, aunque sí contestó por escrito las preguntas que le fueron remitidas, por considerar que los temas de las mismas son propias del ámbito de la ciudad (principio de autonomía

56 Expediente E-005. 
territorial) y no del de la Nación. Para resolver el caso, la Sala comienza por determinar cuáles son los servidores públicos que pueden ser emplazados por las comisiones, a partir de la interpretación de los artículos 115 y 208 de la Carta, para afirmar que los alcaldes, en tanto hacen parte de la rama ejecutiva, sí pueden ser emplazados. Este aserto se matiza enseguida, en razón de la materia, para advertir que dicho emplazamiento procede cuando se trata de un asunto de «interés nacional y no de uno netamente local». A partir de estos elementos de juicio, concluye que la excusa está parcialmente fundada, en cuanto atañe a los asuntos de interés local, pero no lo está respecto de «aquellos asuntos que trascienden ese ámbito territorial para convertirse en asuntos de interés nacional».

Segunda década (2003-2013)

El Auto 186 del 13 de diciembre de $2004^{57}$ la Sala decide no dar curso a la solicitud hecha por la comisión, por entender que en realidad el Director del Departamento Administrativo de Estadística no se ha reusado a asistir a la citación, sino que, además de remitir por escrito la respuesta al cuestionario formulado, manifestó su dificultad de asistir a dicha citación en la fecha inicialmente prevista, por razón de un viaje al exterior (lo que implica una solicitud de aplazamiento o de fijación de nueva fecha y no una excusa, en el sentido del artículo 137 de la Carta).

La segunda decisión de esta década expedida mediante el Auto 131 del 28 de junio de $2005^{58}$ también es la de no dar curso al trámite, por establecerse que no hay evidencia de que la comisión hubiese insistido en el emplazamiento al Alcalde de Medellín, que se había excusado de asistir a la fecha programada en un comienzo y había respondido el cuestionario por escrito. ${ }^{59}$

La tendencia de decidir no dar curso a la solicitud no se modificará en la decisión siguiente, contenida en el Auto 119 del 5 de abril de $2006 .{ }^{60}$ En este caso la razón es que la competencia para emplazar corresponde a las comisiones permanentes, sean constitucionales y legales, «no puede entenderse implícitamente transferida a las comisiones accidentales cuando cumplan misiones específicas para agilizar y facilitar la labor de las Cámaras y sus comisiones permanentes.» ${ }^{61}$

De la anterior decisión se aparta el Magistrado Humberto Antonio Sierra Porto, por considerar que al ejercer la función de control político, la comisión accidental podría tenerse, en una interpretación sistemática de la Constitución y de la Ley, como competente para emplazar personas en los términos del artículo 137 de la Carta.

\footnotetext{
57 Expediente E-006.

58 Expediente E-007.

59 Corte Constitucional de Colombia, Auto 131/05, fundamento jurídico 7.

60 Expediente E-008.

61 Corte Constitucional de Colombia, Auto 119/06, fundamento jurídico 5.
} 
La dinámica de no dar curso, mantiene su inercia en el Auto 155 del 18 de mayo de $2006,{ }^{62}$ por la misma razón que soporta la decisión anterior, esto es, porque la comisión que emplaza es una comisión accidental. ${ }^{63}$ En este caso también se repite la discrepancia del referido magistrado, que esta vez hace una aclaración de voto, para manifestar que si bien acoge el razonamiento de la mayoría, considera necesario reiterar lo ya dicho en su salvamento de voto.

En el Auto 330 del 19 de noviembre de 2008, ${ }^{64}$ si bien se cambia la decisión de no dar curso que había marcado el primer lustro de esta década, en rigor no se toma una decisión de fondo, pues la Sala se limita a constatar que las razones dadas por el Alcalde de Bogotá D.C. para no asistir a la comisión, justifican que se programe una nueva citación, pues en realidad no se había negado a asistir, sino que había manifestado su interés en hacerlo y, al mismo tiempo, su imposibilidad de concurrir en la fecha programada. Esta decisión antedicha no genera mayor interés, sin embargo, de la argumentación de la providencia debe decirse otra cosa, pues la Sala aprovecha la oportunidad para analizar tanto la competencia de las comisiones como la suya propia.

Del análisis del tribunal, más allá de la clasificación de las citaciones del artículo 137 de la Carta como citaciones en general ${ }^{65}$ a particulares o funcionarios ${ }^{66}$ merece la pena destacar dos importantes elementos: la distinción que la Sala hace entre control político y control jurídico ${ }^{67}$ y la afirmación de que tanto la competencia prevista en este artículo corresponde al ejercicio de un control político. ${ }^{68}$

La distinción entre control político y control jurídico se hace a partir de tres criterios: (i) el parámetro de control, (ii) el sujeto que ejerce el control y (iii) la finalidad del control. El parámetro del primero no es un patrón «objetivo, preestablecido e indisponible», sino que depende de la conveniencia, la crítica, el seguimiento informativo, entre otros, mientras que el del segundo sí lo es, al estar configurado sólo por las normas del derecho. El sujeto que ejerce el primero no requiere ni formación ni calificación específica, pues basta su elección como miembro del Congreso y su representación de la voluntad popular, mientras que el segundo debe ser hecho por abogados. La finalidad del primero tiene que ver con cambiar la opinión pública, enterar a los ciudadanos de asuntos de interés, generar debate, etc., mientras que la del segundo es «decir el derecho mediante su resultado que es la decisión judicial, la cual tiene como contenido la declaración del derecho o su rechazo».

En tanto se trata del ejercicio de un control político, el control a cargo de la Corte Constitucional no puede omitir considerar esta circunstancia y, en consecuencia, para juzgar la efectividad de este control, se debe seguir dos importantes criterios: el

\footnotetext{
62 Expediente E-009.

63 Corte Constitucional de Colombia, Auto 155/06, fundamentos jurídicos 7 y 8.

${ }^{64}$ Expediente E-010.

65 Artículos 233 a 236 de la Ley 5 de 1992.

66 Corte Constitucional de Colombia, Auto 330/08, fundamento jurídico 5.

${ }^{67}$ Ibidem, fundamento jurídico 10.

68 Ibidem, fundamento jurídico 10.
} 
de inmediatez y el de inmediación. Dicho esto, se ocupa de precisar el ejercicio de su competencia a partir de diversos escenarios hipotéticos.

Algo semejante ocurre en la decisión sobre la excusa del Alcalde de Medellín, en el Auto 331 del 19 de noviembre de $2008,{ }^{69}$ de la cual vale la pena traer a cuento, lo relativo a la entidad o carácter material de la excusa, que es lo que se debe revisar para juzgar su validez, en los siguientes términos:

La excusa tiene carácter material cuando la persona natural o jurídica expresa que no asistirá a la citación, a partir de argumentos de fondo, destinados a (i) cuestionar la competencia de la comisión para solicitar su comparencia con el objeto de resolver el cuestionario propuesto; o (ii) poner de presente la existencia de motivos de índole constitucional o legal, que impiden declarar sobre la materia de la indagación; por ejemplo, cuando los aspectos objeto de la deposición sean incompatibles con la protección de derechos constitucionales del citado o de terceros. Entre estos eventos puede enumerarse el vínculo entre la información solicitada y la reserva periodística o profesional, o respecto del deber de confidencialidad predicable de determinados actos de los ministros religiosos, entre otras hipótesis. ${ }^{70}$

La primera decisión de esta década en la cual la Sala se pronuncia de fondo sobre una excusa, está contenida en el Auto 149 del 1 de abril de 2009, ${ }^{71}$ por medio del cual se tiene por no válida la que presentó el presidente de una empresa de salud, que había aducido no estar obligado a comparecer por tratarse de una entidad comercial de derecho privado. Luego de recordar que la competencia de las comisiones tiene el propósito de dar la «posibilidad de conocer, con la profundidad que la misma comisión y sus miembros consideren necesaria, información conducente al más efectivo ejercicio de sus funciones» (fundamento 3.3.), el tribunal destaca que éstas pueden emplazar a «toda persona natural o jurídica» y, para estos casos, reconoce la siguiente regla:

[...] la procedibilidad de las excusas que se opongan ha de ser estudiada por esta corporación desde una perspectiva exigente y restrictiva, y aquéllas sólo podrán tenerse por válidas en la medida en que así resulten a la luz de preceptos constitucionales de superior importancia a la facultad de los miembros del Congreso para acopiar la información que juzgue necesaria para el cumplimiento de sus funciones constitucionales y legales. $^{72}$

El presidente de la empresa de salud promovió un incidente de nulidad contra lo actuado, que fue negado por medio del Auto 207 del 27 de mayo de 2009, e interpuso un recurso de reposición contra la providencia que declaró no válida su excusa, el cual se rechazó por improcedente, mediante Auto 217 del 17 de junio de 2009. Dado que es la primera vez en que se recurre este tipo de decisión, la Sala decide

69 Expediente E-011.

${ }^{70}$ Corte Constitucional de Colombia, Auto 331/08, fundamento jurídico 10.

71 Expediente E-012.

72 Corte Constitucional de Colombia, Auto 149/09, fundamento jurídico 3.3. 
establecer la que será la regla aplicable, a partir del Decreto 2067 de 1991, para destacar que el artículo 49 de éste prevé que contra las sentencias no procede recurso alguno y advertir que a los autos que resuelven sobre la validez de las excusas, al ser decisiones definitivas, que agotan la competencia de la Corte, se les debe aplicar la misma regla.

En el Auto 103 del 26 de mayo de $2010,{ }^{73}$ el tribunal retoma la línea característica de la década y decide no dar curso a la solicitud formulada por la comisión, porque esta no insistió en el emplazamiento.

La década concluye con la decisión de declarar fundada la excusa del Alcalde de Bogotá D.C. en el Auto 308 del 29 de julio de 2015, ${ }^{74}$ por considerar que el cuestionario enviado se refiere a «competencias asignadas legalmente a las autoridades locales ${ }^{75}$ como sostiene el Alcalde y, por lo tanto, que no se trata de un asunto que comprometa el interés de la Nación. De esta decisión conviene traer a cuento la síntesis que se hace sobre la competencia del Congreso y la competencia correlativa de la Corte, en los siguientes términos:

Sobre la naturaleza y características de las citaciones previstas en el artículo 137 de la Constitución se puede concluir: (i) se inscriben dentro del principio de separación de las ramas del poder público, con colaboración armónica entre ellas, (ii) hacen parte de los mecanismos de control político, (iii) están limitadas a las células legislativas allí previstas, (iv) se encuentran circunscritas a las personas mencionadas en el estatuto superior, (v) el procedimiento está previsto en la Carta, en la ley 5. de 1992 y en el reglamento de la Corte Constitucional, (vi) el citado tiene derecho a ser escuchado en audiencia privada por la Sala Plena de la Corte, (vii) únicamente el Tribunal Constitucional podrá resolver si las excusas son fundadas o infundadas, (viii) para hacerlo la Corte deberá verificar el cumplimiento de las condiciones previstas en la Carta, (ix) la decisión de la corporación hace tránsito a cosa juzgada, pone fin a la controversia y obliga a las partes. ${ }^{76}$

De esta decisión discrepan, en cuanto su fundamento, dos magistrados, por medio de aclaraciones de voto. El Magistrado Mauricio González Cuervo considera que se debe emplear criterios flexibles para determinar si está o no comprometido el interés de la Nación, como podría estarlo en este caso; que dada la representación que tiene la Cámara de Representantes, que es territorial, debería tenerse, al menos en principio, como improcedente la excusa relativa a que el asunto es local. La Magistrada María Victoria Calle Correa considera que ha debido hacerse explícita en el texto la metodología empleada para la decisión, pues en la decisión precedente (Auto 080 de 1998) el análisis se hizo de todas y cada una de las preguntas y no de modo global, para reconocer que algunos asuntos pueden tener interés nacional e interés local y aplicar entonces el principio de subsidiaridad, conforme al cual, las comisiones pue-

73 Expediente E-013.

${ }^{74}$ Expediente E-014.

75 Corte Constitucional de Colombia, Auto 308/15, fundamento jurídico 10.4.

76 Ibidem, fundamento jurídico 6.2 . 
den «intervenir en el control político de los mandatarios territoriales, cuando la respectiva célula representativa del mismo nivel no lo haga o lo haga de un modo que resulte insuficiente».

Tercera década (2014-2017)

En el Auto 140 del 13 de abril de $2016,{ }^{77}$ al pronunciarse sobre las excusas dadas por diversos servidores públicos, la Sala decide no dar curso a las mismas, salvo a la relativa a la Viceministra de Minas, respecto de quien dice que no está en el deber de atender la citación. Lo primero se debe a que o bien no se insistió en el emplazamiento por la comisión, o bien a que en realidad su excusa no tiene un carácter material, que es la sujeta materia de revisión de la Corte, sino meramente formal, que debe resolverse de otro modo. Lo segundo se debe a que la materia de la citación, que se establece a partir del cuestionario, no guarda relación con las funciones propias de la Viceministra, sino que corresponden a otro viceministerio.

Dada la relevancia del carácter de la excusa, la Sala se remite para caracterizar el carácter material de la misma al Auto 331 de 2008 y emprende una caracterización de su carácter formal. Esta tarea comienza por advertir que una excusa formal es aquella que no implica la negativa a concurrir a la comisión, sino la imposibilidad de hacerlo en determinada fecha. En estos eventos no hay en realidad objeto de control para la Corte, de ahí que la decisión sea no dar curso, sino que el asunto debe ser manejado por la comisión a partir de dos elementos de juicio: el deber prevalente de concurrir a la sesión, que tiene la persona, en tanto se trata de un deber constitucional, y la posibilidad de sancionar a la persona por desacato si la excusa formal se emplea como un instrumento para posponer o demorar (y de este modo negar) la asistencia injustificadamente.

En el Auto 166 del 21 de abril de $2016^{78}$ se decide no dar curso a una remisión de la Procuraduría que tiene que ver con una excusa ante una comisión, porque en realidad no se trata de una excusa sino de una queja disciplinaria que un congresista hace respecto de la inasistencia del Director de la Agencia Nacional de Licencias Ambientales. La Sala cuestiona el emplazamiento, pues no hay en realidad un cuestionario sino apenas la mención de temas generales, el tipo de excusa, que es sólo formal (problemas de agenda le impiden asistir) y la circunstancia de que la comisión no haya insistido en el emplazamiento.

En la decisión más reciente dada en el Auto 543 del 9 de noviembre de 2016, ${ }^{79}$ la Corte retoma uno de los asuntos recurrentes en esta materia, la excusa del Alcalde Mayor de Bogotá D.C., que encuentra justificada respecto de algunas preguntas e injustificada respecto de otras, al distinguir entre ellas a partir del interés nacional

77 Expedientes E-015, E-016, E-017 y E-018.

${ }_{78}$ Expediente E-019.

79 Expediente E-020. 
que pueden concitar. En esta decisión se resume los presupuestos necesarios para que se active la competencia de la Corte, en los siguientes términos:

(i) que una comisión permanente del Congreso de la República emplace a cualquier persona natural o jurídica para que rinda declaraciones orales o escritas, sobre los hechos relacionados directamente con las indagaciones que aquella adelanta; (ii) que el emplazamiento realizado sea debidamente comunicado al citado, en los términos dispuestos en la ley; (iii) que la persona citada se excusare de asistir mediante la formulación de razones de índole material; y (iv) que la respectiva comisión insistiera en citarlo. ${ }^{80}$

A partir de esta base, en el contexto de las funciones del congreso, distingue entre control político y control público, para encuadrar las competencias de las comisiones en este último. El tribunal sostiene que el primero «apunta a toda actividad del órgano colegiado de representación popular tendiente a pedir cuentas, debatir, cuestionar o examinar la gestión y actividades del gobierno y la administración», mientras que el segundo «se focaliza en una posibilidad de emplazamiento a cualquier persona, natural o jurídica, con miras a que rinda declaraciones sobre hechos relacionados directamente con el ejercicio de las funciones que de ordinario cumplen las comisiones permanentes de cada una de las cámaras, obteniendo por esta vía información que cualifique la función parlamentaria.» ${ }^{81}$ Así entendido, el control público se funda, respecto de los particulares, en el deber de colaborar con las autoridades públicas (artículo $95 \mathrm{CP}$ ), y, respecto de los servidores públicos, en la obligación que tienen los diversos órganos de apoyarse para la realización de sus fines (artículo $113 \mathrm{CP}$ ).

De esta decisión discrepan, en cuanto a su fundamento, dos magistrados, por medio de aclaraciones de voto. El Magistrado Luis Ernesto Vargas Silva considera que ha debido ampliarse la regla de que el control de la comisión no se pueda ejercer ni al comienzo, ni durante el trámite, sobre asuntos de carácter local, pues esta tarea corresponde a otros órganos. La Magistrada María Victoria Calle Correa, que destaca el uso de la metodología de análisis individual de cada pregunta, insiste en la necesidad de emplear, cuando el carácter del interés no sea evidente, el principio de subsidiariedad, lo que no se hizo en este caso.

\section{CONCLUSIONES}

La competencia atribuida a las comisiones permanentes de ambas cámaras en el artículo 137 de la Constitución de 1991 es nueva en el texto constitucional y en la tradición constitucional colombiana. Esta competencia puede entenderse como proyección razonable de las reformas constitucionales introducidas por los actos legislativos de 1968 y 1979, y puede verse profundizada en la reforma constitucional de

${ }^{80}$ Corte Constitucional de Colombia, Auto 543/16, fundamento jurídico 1.7.

${ }^{81}$ Ibidem, fundamento jurídico 2.1.2. 
2007. En su diseño inicial por la Asamblea Nacional Constituyente, se consideró que esta competencia era propia de la función de control político del Congreso; sin embargo en la experiencia de la Corte Constitucional se ha llegado a matizar que corresponde a la función de control público a cargo del mismo órgano.

La competencia de la Corte Constitucional para decidir sobre las excusas de que trata el artículo 137 de la Constitución, en el contexto original de la Asamblea Nacional Constituyente se consideró como un control judicial encaminado a proteger los derechos fundamentales del individuo frente a un órgano del Estado. El criterio determinante para establecer el tipo de control judicial que comporta decidir sobre las excusas es la eventual afectación de derechos fundamentales, lo que debe ser verificado de manera empírica en los casos hasta ahora acaecidos.

La experiencia de veinte casos tramitados por la Corte Constitucional permite afirmar que cuando la excusa es verdaderamente tal, es decir, cuando la excusa tiene un carácter material, implica la consideración de derechos fundamentales y de principios constitucionales, con lo cual no se puede negar que se trata de un tipo de control de constitucionalidad de manera tajante, así subsistan algunos matices desde lo teórico. La norma que resulta de esta experiencia, tiene unos perfiles mucho mejor definidos que los del enunciado normativo inicial y los razonamientos originales en torno a él, y muestra un sentido más amplio en ciertos aspectos y más estricto en otros.

El sentido amplio se predica, a partir de esta experiencia, del titular de la competencia (puede ser una comisión constitucional o legal, siempre y cuando sea permanente); de su objeto (no sólo se refiere a las indagaciones de la comisión, sino a cualquier otra función del Congreso, para la cual se requiera obtener información relevante); del tipo de control (puede empezar siendo público, pero devenir en político, o en el ejercicio de otra función del Congreso); de la persona sobre la que recae (puede ser un particular o un servidor público, e incluso una persona jurídica); del deber de atender el emplazamiento (que se califica como un deber constitucional prevalente).

En sentido estricto se predica, también a partir de esta experiencia, de la conexidad (relación directa) necesaria entre las competencias misionales de la comisión y los hechos que motivan el emplazamiento, verificables en el cuestionario; del compromiso de un interés nacional y no netamente local, para preservar el principio de autonomía de los entes territoriales; del carácter material y no meramente formal de la excusa; del estándar riguroso para tener una excusa como válida (que así resulten a la luz de preceptos constitucionales de superior importancia a la facultad de los miembros del Congreso para acopiar la información); de una serie de requisitos formales rigurosos (emplazamiento por una comisión permanente sobre hechos directamente relacionados con las indagaciones, emplazamiento debidamente comunicado, excusa de carácter material e insistencia de la comisión en el emplazamiento).

En la referida experiencia se observa también una progresiva y evidente dificultad para tramitar las excusas, pues no es por casualidad que en los últimos años la decisión más repetida haya sido la de no darles curso, que revela o bien un ejercicio desprolijo 
de su competencia por las comisiones, o un rigor creciente en las exigencias de la Corte, o ambas cosas al mismo tiempo.

\section{BIBLIOGRAFÍA}

Asamblea Nacional Constituyente, Reglamento, 1991.

Cifuentes Muñoz, Eduardo, «La Justicia Constitucional en Colombia», en: Anuario Iberoamericano de Justicia Constitucional, No. 1, 1997, p. 3.

Congreso de Colombia, Ley 5 de 1992, Ley orgánica «Por la cual se expide el Reglamento del Congreso; el Senado y la Cámara de Representantes».

Corte Constitucional de Colombia

Acuerdo 2 del 22 de julio de 2015, «Por medio del cual se unifica y actualiza el Reglamento de la Corte Constitucional».

Auto 23 del 17 de septiembre de 1992

Auto 006 del 20 de mayo de 1993

Auto del 10 de octubre de 1995

Auto 080 del 14 de diciembre de 1998

Auto 186 del 13 de diciembre de 2004

Auto 131 del 28 de junio de 2005

Auto 119 del 5 de abril de 2006

Auto 155 del 18 de mayo de 2006

Auto 330 del 19 de noviembre de 2008

Auto 331 del 19 de noviembre de 2008

Auto 149 del 1 de abril de 2009

Auto 207 del 27 de mayo de 2009

Auto 217 del 17 de junio de 2009

Auto 103 del 26 de mayo de 2010

Auto 010 del 17 de febrero de 2004

Auto 308 del 29 de julio de 2015

Auto 140 del 13 de abril de 2016

Auto 166 del 21 de abril de 2016

Auto 543 del 9 de noviembre de 2016

Sentencia C-600 del 21 de octubre de 1998

Sentencia C-049 del 7 de febrero de 2012

Sentencia C-173 del 9 de marzo 2014

Gamper, Anna y Palermo, Francesco, «The Constitutional Court of Austria: Modern Profiles of an Archetype of Constitutional Review», en: Andrew Harding y Peter Leyland (eds.), Constitutional Courts: A Comparative Study. London, Wildy, Simmons \& Hill, 2009, pp. 31-43.

Garcés LoredA, María Teresa, De la Administración de Justicia, 1991, Disponible en: http://babel.banrepcultural.org/cdm/ref/collection/p17054coll28/id/341 
García-Pelayo, Manuel, «El Status del Tribunal Constitucional», Revista Española de Derecho Constitucional, No. 100, 2014, pp. 15-37.

Garoupa, Nuno y Ginsburg, Tom, «Judicial Roles in Nonjudicial Functions», Washington University Global Studies Law Review, Vol. 12, 2013, pp. 755-782.

Garoupa, Nuno, y Ginsburg, Tom, «Building Reputation in Constitutional Courts: Political and Judicial Audiences», Arizona Journal of International and Comparative Law, Vol. 28, No. 3, 2011, pp. 539-568.

Ginsburg, Tom, y Elkins, Zachary, «Ancillary Powers of Constitutional Courts», Texas Law Review, Vol. 87, 2008-2009, pp. 1431-1461.

GonZÁlez Quintero, Rodrigo, Pactos Constitucionales y Control Constitucional: Una Aproximación desde el Derecho Comparado, México D.F., Porrúa, 2017.

GroppI, Tania, «The Italian Constitutional Court: Towards a Multilevel System of Constitutional Review», en: Andrew Harding y Peter Leyland (eds.), Constitutional Courts: A Comparative Study. London, Wildy, Simmons \& Hill, 2009, p. 127.

Kommers, Donald y Miller, Russell, «Das Bundesverfassunggsgericht: Procedure, Practice and Policiy of the German Federal Constitutional Court», en: Andrew Harding y Peter Leyland (eds.), Constitutional Courts: A Comparative Study. London, Wildy, Simmons \& Hill, 2009, pp. 102-112.

Lleras de la Fuente, Carlos, Arenas Campos, Carlos Adolfo, Charry Urueña Juan Manuel y Hernández BeCERra, Augusto, Interpretación y génesis de la Constitución de Colombia, Bogotá, Cámara de Comercio de Bogotá, 1992.

Holguín Sarria, Armando y Abello Roca, Carlos Daniel, Informe de minoría, 1991, Disponible en: http://babel.banrepcultural.org/cdm/ref/collection/ p17054coll28/id/290

Moreno Ortiz, Luis Javier, La moción de censura en Colombia: historia de una heterodoxia, Revista del Instituto de Estudios Constitucionales de la Universidad Sergio Arboleda, Núm. 12, 7-77, 2008.

Palacio Rudas, Alfonso, Ponencia sobre la función de control político del Congreso, 1991, Disponible en: http://babel.banrepcultural.org/cdm/singleitem/collection/ p17054coll28/id/344/rec/1.

Ponthoreau, Marie y Hourquebie, Fabrice, «The French Conseil Constitutionnel: An Evolving Form of Constitutional Justice», en: Andrew Harding y Peter Leyland (eds.), Constitutional Courts: A Comparative Study. London, Wildy, Simmons \& Hill, 2009, pp. 81-89.

Presidencia de la República de Colombia, Decreto 2067 de 1991, Decreto con fuerza de ley «por el cual se dicta el régimen procedimental de los juicios y actuaciones que deban surtirse ante la Corte Constitucional».

Velasco Guerrero, José María, Informe presentado por José María Velasco Guerrero sobre Consejo de Estado, Corte Suprema de Justicia y control jurisdiccional de constitucionalidad, 1991, Disponible en: http://babel.banrepcultural.org/cdm/ref/collection/ p17054coll28/id/295 
Title:

Colombian Constitutional Court's ancillary powers: an approach to its decisions regarding refusal to attend congress' hearings

\title{
Summary:
}

Introduction. I. An Approach to the Colombian Judicial Review System. II. Ancillary Powers to Judicial Review: Debates and Adoption at the Constitutional Assembly. III. Ancillary Powers to Judicial Review in the Constitutional Court's Case Law. IV. Ancillary Powers to Judicial Review in Comparative Law. V. Constitutional Court's Decisions regarding Excuses for Subpoenas. Nature. Holdings. VI. Conclusions. Bibliography

\section{Resumen:}

Este artículo se centra en la poco explorada cuestión las competencias secundarias de la Corte Constitucional colombiana, en especial sobre la competencia de decidir sobre las excusas a los emplazamientos que hace el Congreso en ejercicio de su control político y público. Para este propósito se estudia el origen de esta competencia en la Asamblea Nacional Constituyente, se la analiza en el contexto de otras experiencias constitucionales y se considera, a partir de fuentes teóricas (normativas y doctrinales) y evidencia empírica (estudio de casos), dos hipótesis sobre su naturaleza y alcance, para concluir que se trata de una competencia jurisdiccional, que se concreta en una providencia judicial que hace tránsito a cosa juzgada, y que puede tenerse como una modalidad especial del control de constitucionalidad.

\begin{abstract}
:
This article is focused on the ill studied topic of the Colombian Constitutional Court's ancillary powers, and especially on its decisions regarding a person's refusal to attend hearings related to Congress' control functions. Thus, the text begins with the origins of this power discussed at the constituent assembly, then analyzing it in Comparative Constitutional Law. Also taking into account both theoretical and practical elements - such as doctrine, norms and case law_-, it does propose two hypotheses concerning its character and effects, concluding that entails an exercise of judicial power with res iudicata force and that it comprises a especial type of judicial review.
\end{abstract}

\section{Palabras clave:}

Derecho Constitucional Comparado, Control político, Control Constitucional, Poderes Secundarios o Adjuntos.

\section{Key words:}

Comparative Constitutional Law, Political Control, Judicial Review, Ancillary Powers. 